\title{
The Current Situation Analysis and Development Strategy of Traditional Retail Industry under Electronic Commerce
}

\author{
Ye Liang \\ Shaanxi College of communication technology, Xi'an, Shaanxi, 710018
}

Keywords: Electronic Commerce, Traditional Retail Industry, Current Situation, Development

\begin{abstract}
At present, the e-commerce platform has fundamentally changed the way of people's shopping, which has brought a huge impact on the traditional retail industry. This paper introduces the development status of traditional retail business under e-commerce, analyzes the existing problems and causes and explores the development strategy of traditional retail industry.
\end{abstract}

\section{Introduction}

Retail industry refers to the process of selling consumer goods and providing services to consumers in the form of trading and agricultural products. Retail business includes not only physical goods, but also logistics, installation, maintenance and other services [1]. At present, the traditional retail industry faces many challenges, especially with the development and popularization of e-commerce, which has a great impact on the traditional retail industry.

\section{The Clothing Brand Core Value Construction}

\subsection{The Development of Traditional Retail Industry under Electronic Commerce}

\subsubsection{A constant tide of closing the door}

In recent years, China's electronic commerce has developed rapidly. According to the study, the average growth rate of online shopping in China has been 96\% since 2010. In the first half of 2016, the total retail sales amounted to 2 trillion yuan, while Tmall's "double eleven" business volume was 120 billion 700 million yuan, reaching the top 20 sales centers in the country. E-commerce almost affects all sectors of the retail industry, causing a sharp decline in sales of retail stores, and a large number of stores closed down. According to the industry market demand and investment advisory report of Chinese retail enterprises from 2016 to 2021, only in the first half of 2016, 22 businesses in traditional retail businesses closed 41 stores, and the total area of business closure was over 690 thousand square meters [2]. For example, WAL-MART China, a large shopping supermarket, closed 5 stores in 2012, closed 15 in 2013, closed 16 in 2014, and closed 14 in 2015 and 2016. Besides, the development of traditional retailing industry in China is uneven. The traditional department stores and home appliance retailers are most impacted by e-commerce, while the traditional retail businesses such as convenience stores and fresh stores are less affected.

\subsubsection{Middle and high end passenger source loss}

About $80 \%$ of e-commerce customers in China are young customers. They are the most commercial and dynamic groups, accounting for over $40 \%$ of the total consumption of the network. Among them, customers who spend more than ten thousand yuan a year account for 70\% [3]. Comparatively speaking, most of the old and old customers who are accustomed to shopping in the traditional retail industry are more frugal, and the per capita consumption limit is not high. The loss of high-end customers and part of the high-end commodity sales market has exacerbated the passive development of traditional retail industry. 


\subsection{The Existing Problems and Reasons of Traditional Retail Business under Electronic Commerce}

\subsubsection{High Cost}

The cost of traditional retail is mainly by the purchase price of goods, store rent, staff salaries, logistics and transportation, warehousing costs and interior decoration and other aspects. Under the background of the increasing cost of our country, the cost of traditional retailing and the decrease of profits, especially the increase of rent and manpower cost of stores, have become an important factor that restricts the development of traditional retailing industry. In recent years, real estate prices in China have surged [4]. Although the upward trend is slowing down, there is no downward trend. According to the survey, rent cost accounts for 30\%-50\% of the total operating cost of retail businesses such as supermarkets, stores and convenience stores. At the same time, human costs have increased year by year, especially in the two or three line city retail industry, and the cost of manpower has exceeded the rent. In 2015, the manpower cost of the large supermarket accounted for $35 \%$ of the total operating cost, and the proportion of young employees into the retail industry decreased, resulting in the lack of human resources [5]. The trading platform of e-commerce is a shopping website instead of an entity shop, which greatly reduces the cost of rent. E-commerce sellers can use a small number of personnel to meet the consumers' exchange, order, delivery and other processes, saving the labor cost.

\subsubsection{Lack of marketing means}

The main marketing means of the traditional retail industry are commodity display, advertising and promotion. In terms of display goods, they are usually placed on the basis of consumers' shopping habits, such as high sales volume, high brand awareness and promotional products will generally be placed in a conspicuous place, so that consumers can successfully find out. Commodity advertisements are displayed to consumers through outdoor display boards, TV, newspapers, etc., or direct communication between employees and consumers [6]. Retailers will regularly organize promotional activities to attract consumers through commodity price reduction. Electronic commerce can enable consumers to enter the shopping website to browse through pictures and video, information about the types of goods, price and usage, the use of such methods, and according to the sales price, and the scores of intelligent sorting, than employees of the retail enterprise to sell more persuasive oral. E-commerce can be launched through advertising portal search engine, especially mobile APP software push advertising information, advertising update fast, low cost, high efficiency of consumer browsing.

\subsubsection{The relatively weak ability to resist risk}

First of all, China's large retail businesses mostly take the high-end line, mainly rely on the international first-line brand, and are in a passive position in cooperation with suppliers. There are many supply links and the price formation chain is long, resulting in high transaction costs. The retail industry in the same area mostly introduces the same brand, and the brand goods of each retail enterprise are much the same [7]. It is easy to make consumers feel aesthetic fatigue. Secondly, in terms of capital flow, the traditional retail industry needs a large number of commodity reserves, and it needs to display products one by one, resulting in a large number of goods being pressed, resulting in inconvenient circulation of funds, which is easy to cause cost loss when prices and funds fluctuate. Finally, the consumer groups in the traditional retail industry are mainly nearby residents, which are affected by local economic fluctuations and residents' income. Electronic commerce only needs to publish pictures in online shops when goods are displayed [8]. When goods are traded, they can be directly connected to suppliers and consumers, so they can take the way of presale. After receiving the consumer order, the supplier is ordered, the transaction is more flexible, the cost is low, and a lot of warehousing is avoided, and online transactions break through the geographical restrictions, which can quickly and effectively resist risks. 


\subsubsection{Incomplete types of goods}

Traditional large retail businesses take "large and full" as their main business characteristics. The dazzling products can make consumers enjoy the pleasure of shopping, but the types of retail businesses are dwarfed by e-commerce and no longer have competitive advantages. Although the types of products displayed in the traditional retail trade are all comprehensive, but because of the limitation of the shopping space, we can only choose some famous brands or representative, good reputation products, but the types of goods under e-commerce can be said to contain everything [9]. Consumers can easily get products from all regions and brands, and consumers can buy goods by overseas purchasing. The price and quality are more advantageous than those of local retailers.

\subsubsection{Poor information search}

Because of the inability to apply the information network technology in the traditional retail industry, the methods of data collection and analysis are single, insufficient and inefficient. It is difficult to analyze consumer's behavioral data and analyze the psychological characteristics of consumers, and it is easy to produce forecast deviation for future operation. E-commerce can use big data to locate consumers accurately, and record and sort out information related to consumption types, locations, time and preferences [10]. Sellers and suppliers can adjust business plans in time according to their purchase records and user evaluations, providing consumers with different commodity functions and ways of purchase. In the category of goods, prices, channels and sales strategy more targeted, to improve the efficiency of enterprise management and sales profit.

\subsubsection{Poor experience in transaction services}

First of all, in terms of transaction efficiency, the traditional retailing industry is scattered, with limited category, type and quantity, sometimes causing consumers to go empty handed. E-commerce can enable consumers to choose goods with purpose, and is more likely to meet consumers' requirements. Secondly, the traditional retail industry can support the trial and trial of goods. With the improvement of e-commerce after sale service, consumers can get the same even higher service experience. Tmall has quality assurance, freight insurance and other services, supports seven days, no reason to return goods, consumers can also access to goods, avoid taking the cost of return logistics [11]. At the same time, consumers can score online stores, give good comments or bad reviews, so that e-commerce services are more thoughtful. Finally, most of the traditional retail stores are not open 24 hours, they can't satisfy consumers' demand for shopping at any time, and holidays are too crowded and too crowded. E-commerce can enable consumers to shop anywhere, anytime.

\subsubsection{Change of consumer's consumption habits}

The development of traditional retail and e-commerce is related to the upgrading of consumption in China. In the process of urbanization, the living standard of Chinese residents has significantly improved, and the way of life has also changed. When the economic level is low, people are more and more satisfied with the quantity of commodities. Currently, the proportion of people living to meet the needs of life is decreasing, and the demand for other attributes of commodities is increasing. In the traditional retail trade process, consumers need to pay more time and traffic cost when choosing goods. During holidays, supermarkets and other retail businesses are overcrowded and have poor consumption experience. E-commerce can enable consumers to purchase goods at home and make goods easier than three stores, comparing the price and evaluation of the same goods in different stores, so as to get the goods with the highest cost performance. In addition, the popularity of intelligent mobile phone and WeChat, Alipay and other three party mobile payment software application, improve the convenience, mobility and timeliness of electronic commerce.

\subsection{The Development Strategy of Traditional Retail Business under Electronic Commerce}

\subsubsection{Give full play to the advantages of traditional retail industry}

Under electronic commerce, the traditional retail industry is facing various unfavorable 
situations, but it still has its own advantages. First of all, the traditional retail industry has the established brand, easy to play the brand effect. Some stores have been in operation for years to decades. Consumers are familiar with and used to use some commodity brands, forming the habit of shopping in shopping malls, but there are too many kinds of e-commerce products, so it is difficult to build impressive brands. Secondly, physical shops can give consumers a sense of security, and face-to-face communication between employees and consumers is easy to establish trust. E-commerce transactions are prone to network fraud. Thirdly, in terms of purchase experience, although e-commerce supports returns, but the cost of time is too high, consumers can get in touch with goods in traditional retail businesses, and have rich sensory experience. Finally, the traditional retail industry has a certain social function, and with friends and relatives in the supermarket shopping is a popular way of leisure and entertainment. The traditional retail industry should give full play to these advantages and bring better shopping experience to consumers.

\subsubsection{Online and offline integration management}

The traditional retail industry should consider how to reduce the cost of rent, labor and logistics to improve the final profit. Therefore, the traditional retail industry needs to absorb the experience of e-commerce operation, and use information network technology to implement online and offline integration operation to meet the needs of different consumer groups, so as to achieve the goal of increasing sales volume and increasing profits. First of all, the implementation of line and line on the line of differential operation, according to the consumer groups to formulate different sales strategies. For example, the Internet can low-end commodity business, the main service object is to pursue low price oriented consumers, with low prices and a large number of development strategies; the line store can operate in general merchandise, mainly in the consumer demand for high-grade commercial customers, sales mainly in high income population. On line and under line, independent business should be carried out to avoid conflicts or overlaps in sales channels. Secondly, the implementation of online and offline replenish operation, the economic role played by the integration of traditional retail and e-commerce is greater than the traditional retail business's economic benefits alone [12]. For example, can be used to order online and offline transactions for sale, consumers can according to the retail enterprise posted on the website of the commodity information, ordering and payment, online payment vouchers and then carry to the nearby retail enterprises or cooperative enterprises to pick up, save the time and cost of logistics, goods can further obtain a price advantage. When the traditional retailing industry is integrated with e-commerce, the network platform can be developed by itself, and it can also be cooperated with the existing mature e-commerce platform. For example, WAL-MART and Jingdong business city cooperate fully, the retail enterprises such as Tesco, Suguo supermarket and other retail enterprises hand in with the US group. The cooperation with the existing electric business has not only reduced the difficulty of carrying out the online business, but also can obtain a large number of customers.

\subsubsection{Establishing a modern logistics system}

In the long-term development process of traditional retail industry, most of the distribution centers have been set up with reasonable layout and sound function. Under the background of continuous improvement of consumer logistics demand, we need to improve the degree of information and automation of logistics distribution, reduce inventory and logistics costs, speed up capital turnover, and play the advantage of mature logistics system. According to the consumer address, the distribution center will be chosen to deliver the goods to the customers in a timely and accurate way. Some small retail enterprises can choose the high prestige logistics enterprises to carry on the deep cooperation, carry out the entrusted operation and realize the common development. We should strengthen information construction, improve data acquisition, transmission and analysis capabilities, grasp the subtle changes in the market, adjust business strategies in a timely manner, and improve the operational efficiency of enterprises.

\subsubsection{Improve the quality of service}

The traditional retail industry should grasp the life concept of modern people, reflect the trend of 
the times and popular trend and integrate into the regional characteristics. First of all, we should give full play to the advantages of face to face services, strengthen pre-sale, sale and after-sale services, understand consumers' needs in time, and provide personalized services for consumers, such as whole process shopping guide, special care for disabled persons. Secondly, according to the rational layout of the consumer groups, such as the division of boutique department stores, popular department stores, discounted department stores and other areas; Finally, the shopping center will integrate the shopping, catering, leisure and entertainment into a multi-functional group and develop, strengthen the social functions that e-commerce does not possess, and stimulate consumers' desire to shop in a specific environment.

\section{Conclusions}

To sum up, the development of e-commerce has caused severe impact on the traditional retail industry, but it also brings new opportunities. While developing their own advantages, the traditional retailing industry should take advantage of the advanced experience of e-commerce, strengthen the integration and operation of them, and reform the way of operation, which will bring new vitality to the development of traditional retailing.

\section{References}

[1] Zhang T T, Yin-Pei M A. The Current Situation Analysis and Development Strategy of Port Development in Hainan [J]. Logistics Engineering \& Management, 2015.

[2] Xia Q S. Analysis of the Current Situation of Electronic Commerce of Characteristic Agricultural Products in Suzhou [J]. Journal of Dezhou University, 2017.

[3] Zhang J, Li S. Analysis on Current Situation and Countermeasure of Domestic Electronic Commerce Logistics in the Internet Age_-Based on Resource Dependence Theory[C]// 2017:02066.

[4] $\mathrm{Fu} \mathrm{X}$. The current situation of and a development strategy for traditional Chinese medicinal materials in Luotian County [J]. Journal of Huanggang Normal University, 2016.

[5] Gao S. Analysis of current situation and development of traditional Chinese medicine and western medicine [J]. China Journal of Traditional Chinese Medicine \& Pharmacy, 2016.

[6] Xiao-Huan W U, Peng C Y, Yuan P. Research on the Current Situation and Development Strategy of Natural Graphite Industry in Foreign Countries[J]. China Non-Metallic Minerals Industry, 2016.

[7] Liu Y, Xin X U. Analysis on the Current Situation and Development Strategy of China's Investment Banking [J]. Journal of Hubei University of Technology, 2017.

[8] Wei Y, Huang J, Gu X, et al. Current Situation and Development Strategy of Quinoa Industry in Gansu Province[J]. Crops, 2016.

[9] Lin M D, Xun-Fang X U. Analysis on the Current Situation and Development Strategy of Off-campus Learning Center of Modern Distance Education_-Taking Jiangsu Province as an Example[J]. Adult Education, 2017.

[10] You X, Song S. The Traditional Furniture Retail Coexist with E-commerce Online Sales [J]. Furniture \& Interior Design, 2016.

[11] Xiao-Qian M A. The Channel Conflict and Management Strategy of O2O Network Marketing Pattern under the Electronic Commerce Environment [J]. 2017(icesd).

[12] Yicai L I. Strategy of Competitiveness Improvement of Retail Chain Pharmacies in China under the Impact of Pharmaceutical Electronic Commerce [J]. China Pharmacy, 2016. 